\title{
Erratum to: A causal network analysis in an observational study identifies metabolomics pathways influencing plasma triglyceride levels
}

\author{
Azam Yazdani $^{1} \cdot$ Akram Yazdani $^{1} \cdot$ Ahmad Samiei $^{2} \cdot$ Eric Boerwinkle $^{1}$
}

Published online: 20 September 2016

(C) Springer Science+Business Media New York 2016

Erratum to: Metabolomics (2016) 12:104

DOI 10.1007/s11306-016-1045-2

The original version of the article unfortunately contained a mistake. The name of the third author was incorrectly spelled as "Ahmad Saniei." The author name is corrected through this erratum.

The online version of the original article can be found under doi:10.1007/s11306-016-1045-2.

Azam Yazdani

azam.yazdani@uth.tmc.edu

1 Human Genetics Center, University of Texas Health Science Center, 1200 Pressler Street, Houston, TX 77030, USA

2 Hasso Plattner Institute, 14482 Potsdam, Germany 